\title{
HUBUNGAN EFIKASI DIRI, GAYA BELAJAR, DAN LINGKUNGAN TEMAN SEBAYA DENGAN PRESTASI BELAJAR EKONOMI SISWA KELAS XI IPS SMAN 1 KEDAMEAN
}

\author{
Kumala Dwi Anggraini \\ Program Studi Pendidikan Ekonomi, Fakultas Ekonomi, Universitas Negeri Surabaya \\ Email : \\ Kumalaanggraini@mhs.unesa.ac.id \\ Prof. Drs. Yoyok Soesatyo, S.H., M.M., Ph.D. \\ Program Studi Pendidikan Ekonomi, Fakultas Ekonomi, Universitas Negeri Surabaya \\ Email : \\ yoyoksoesatyo@unesa.ac.id
}

\begin{abstract}
Abstrak
Penelitian ini mempunyai tujuan untuk mengetahui adakah hubungan antara efikasi diri dengan prestasi belajar ekonomi siswa kelas XI IPS SMAN 1 Kedamean, untuk mengetahui hubungan antara gaya belajar dengan prestasi belajar ekonomi siswa kelas XI IPS SMAN 1 Kedamean, dan untuk mengetahui hubungan antara lingkungan teman sebaya dengan prestasi belajar ekonomi siswa kelas XI IPS SMAN 1 Kedamean. Sampel dalam penelitian ini adalah sebanyak 94 peserta didik. Teknik analisis yang digunakan dalam penelitian ini adalah analisis korelasi product moment. Jenis penelitian yang digunakan adalah eksplanatori dengan pendekatan kuantitatif. Berdasarkan penelitian terdapat hubungan yang signifikan antara efikasi diri dengan prestasi belajar ekonomi siswa kelas XI IPS SMAN 1 Kedamean, terdapat hubungan yang signifikan antara gaya belajar dengan prestasi belajar ekonomi siswa kelas XI IPS SMAN 1 Kedamean, dan terdapat hubungan yang signifikan antara lingkungan teman sebaya dengan prestasi belajar ekonomi siswa kelas XI IPS SMAN 1 Kedamean.
\end{abstract}

Kata Kunci: Efikasi Diri, Gaya Belajar, Lingkungan Teman Sebaya, Prestasi Belajar.

\section{Abstract}

This study aims to determine the relationship between self-efficacy and economic learning achievement of XI IPS class students of SMAN 1 Kedamean, to determine the relationship between learning styles and economic learning achievement of XI IPS students at SMAN 1 Kedamean, and to determine the relationship between peers' environment and learning achievement economics of class XI IPS students at SMAN 1 Kedamean. The sample in this study was 94 students. The analysis technique used in this study is product moment correlation analysis. The type of research used is explanatory with a quantitative approach. Based on the results of the study, it is known that there is a significant relationship between selfefficacy and economic learning achievement of XI IPS class students of SMAN 1 Kedamean, there is a significant relationship between learning styles and economic learning achievement of XI IPS students at SMAN 1 Kedamean, and there is a significant relationship between the environment peers with economic learning achievements of class XI IPS students at SMAN 1 Kedamean. Keywords: Self Efficacy, Learning Style, Peer Environmen, Learning achievemet.

\section{PENDAHULUAN}

Pendidikan adalah investasi yang sangat penting didalam pembangunan suatu negara sebab dengan adanya orientasi pendidikan yaitu untuk meningkatkan kualitas sumberdaya manusia sebagai pelaku dalam pembangunan untuk mewujudkan pendidikan yang berkualitas, berbagai upaya telah dilakukan pemerintah melalui lembaga atau institusi formal seperti sekolah. Kegiatan belajar sekolah adalah kegiatan utama karena keberhasilan tujuan pendidikan adalah dipengaruhi oleh proses belajar yang dialami siswa disekolah. Terkait didunia pendidikan untuk tercipta manusia berkualitas yang mempunyai prestasi yang tinggi, maka siswanya juga harus mempunyai prestasi belajar yang baik juga.

Prestasi belajar adalah indicator yang bias dipakai guna mengetahui keberhasilan dari belajar siswa. Dengan prestasi belajar baik maka dapat menggambarkan kualitas dari pendidikan yang baik pula, indikatornya yang digunakan untuk mengukur prestasu belajar ekonomi adalah dari raport semester ganjil.

Berdasarkan penelitan yang dilakukan peneliti ketika observasi nilai raport siswa kelas XI IPS SMAN 1 Kedamean dikategorikan kurang maksimal dilihat bahwa masih ada prestasi belajar ekonomi siswa yang nilainya masih dibawa (KKM). SMAN 1Kedamean menetapkan 
KKM pelajaran ekonomi sebesar 75. Sedangkan masih terdapat 36 siswa dari 123 siswa yang belum memenuhi nilai diatas Kriteria Ketuntasan Minimal (KKM). Nilai ekonomi juga tergolong cukup rendah dari nilai mata pelajaran yang lain. Pada kelas XI IPS di SMAN 1 Kedamean terlihat fenomena siswa di SMA kurang untuk mengekspresikan dirinya yang membuat mereka merasakan tidak nyaman serta tidak memiliki rasa percaya diri dalam meningkatkan potensinya. Ketidakmampuannya dalam mengenali dirinya akan menjadikan keyakinan dirinya yang diperoleh semakin kecil. Menurut Winkel dalam Bekti (2014) ada beberapa factor yang dapat memberikan pengaruh prestasi belajar siswa yaitu factor internal, factor eksternal, factor internal adalahmencakup intelegensi, motivasi, sikap atau gaya belajar, efikasi diri, minat, serta kondisi fisik, kemudian faktor eksternal sendiri adalah mencakup lingkungan keluarga, lingkungan sekolah dan juga lingkungan teman sebaya. Dan satu factor internal yang bias mempengaruhi prestasi belajar siswa adalah efikasi diri.

Sama halnya yang dikemukakan oleh Ferdiyanto(2012) bahwa efikasi diri merupakan suatu persepsi dari setiap seseorang atas keyakinan serta kemampuan dirinya guna hal yang akan diharapkan. Menurut Ghufron (2014) efikasi diri merupakan evaluasi dari dalam diri setiap individu dalam keemampuan pada dirinya dan kompetensi dirinya dalam menghadapi tugas, tujuan yang akan dicapai serta untuk mengatasi hambatannya, sedangkan jika menurut Reivich dan shate dalam Wahyuni (2014) dia menyatakan bahawa efikasi merupakan keyakinan serta kemampuan yang ada pada diri setiap individu guna berhadapan dengan suatu masalah dan memecahkan suatu masalah dengan efektif. Indikator efikasi diri yang digunakan dirujuk dari Bandura dalam Arifin (2014) yang meliputi tingkat kesulitan, generalisasi, dan kekuatan. Hal penting lainnya selain efikasi diri yaitu gaya belajar yang juga menjadi variabel penting dalam mempengaruhi keberhasilan dalam proses pembelajaran. Menurut Keefe dalam Kiranjit (2011) gaya belajar merupakan ciri kognitif, afektif serta psikologis sebagai indicator yang relative stabil. Dengan bagaimana tentang peserta didik memandang dalam berinteraksi serta merespone lingkungan belajarnya. Gaya belajar merupakan kunci dalam meningkatkan motivasi serta potensi belajar seseorang dalam mengerjakan tugas rumah, dan juga dalam situasi social kemasyarakatan.

Menurut oleh Gunawan (2004) menyatakan bahwa gaya belajar adalah cara yang dapat disukai setiap individu guna melaksanakan hal berfikir, memproses serta memahami informasi. Sedangkan jika menurut Barbara dalam Junieris (2015) gaya belajar meruapakan setiap individu untuk berfikir, menyerap, serta menerima informasi yang baru serta sulit. Indikator gaya belajar yang digunakan dirujuk dari De Potter (2009) yaitu: yang pertama Gaya belajar visual adalah mencakup kerapian dan keteraturan, kecepatan di dalam berbicara, perencanaan dan pengaturan, serta ketelitian dan cara mengingat, yang kedua adalah gaya belajar auditorial mencakup tingkat konsentrasi saat belajar, kesulitan dalam menulis, kesenangan dalam mebaca, dan kesenangan dalam mendengarkan, selanjutnya yang ketiga adalah gaya belajar kinestetik adalah mencakup kecepatan dalam berbicara, menanggapi perhatian fisik, orientasi gerak dan fisik, dan juga belajar dengan menggunakan praktik

Kemampuan siswa untuk mengerti serta memahami pelajaran berbeda dalam tingkatannya, apapun gaya belajar yang mereka pilih, perbedaan itu akan memperlihatkan cara yang cepat juga yang terbaik dalam diri setiap individu agar dapat menerima informasi yang bearda diluar dirinya Namun akan tetapi terdapat alasan penyebab gaya belajar siswa rendah, berdasarkan dari hasil pengamatan yang dilaksanakan di kelas XI IPS SMAN 1 Kedamean penyebabnya adalah ketidaknyamanan dalam hal belajar. Siswa lebih senang belajar melalui dengan gambar yang unik atau bisa dengan pengalaman. terkadang ada siswa yang tidak senang dengan cara mengajar guru yang menerangkan teori, ada juga siswa yang suka belajar melalu pendengaran sambil mencoret kertas, pada dasarnya siswa adalah mempunyai gaya belajar masing-masing.

Yang terpenting lainnya selain efikasi dan juga gaya belajar adalah faktor eksternal yaitu lingkungan dalam teman sebaya siswa, Slavin (2008) mengungkapkan "Lingkungan teman sebaya merupakan suatu interaksi dengan orang - orang yang mempunyai kesamaan dalam usia dan status". Lingkungan teman sebaya bisa memberi dampak positif dan negative. Menurut Rosenblum dalam Desmita (2014) ligkungan teman sebaya adalah lingkungan yang lebih menekankan pada kesamaan tingkah laku dan psikologis, sedangkan jika menurut oleh John W Santrock (2009) lingkungan teman sebaya adalah individu yang memiliki tingkatan umur juga kedewasaannya mempunyai tingkatan yang sama.Indikator lingkungan teman sebaya yang digunakan dirujuk dari Desmita (2014) yaitu: yang pertama interaksi social dilingkungan teman sebaya, yang kedua adalah keterlibatan suatu individu dalam berinteraksi, yang ketiga dukungan oleh teman sebaya, yang keempat adalah menjadi teman belajar siswa dan yang ke lima adalah meningkatkan harga diri siswa

Lingkungan teman sebaya dapat ditemukan disekolah, dikelas maupun dilingkungan tempat tinggal. Kedekatan teman sebaya dapat membentuk suatu kelompok yang erat.Relasi anatar lingkungan teman sebaya bereperan penting dalam perkembangan social setiap individu. Lingkungan teman sebaya memberi semangat agar meningkatkan prestasi siswa. Tetapi siswa mengalami problem kesulitan memahami pelajaran ekonomi yang dipengaruhi oleh lingkungan teman sebaya siswa menganggap pelajaran ekonomi sangat membosankan. Siswa kelas XI IPS memiliki masalah dengan lingkungan teman sebayanya. Yang utama adalah didalam suatu kelas. Ketika proses belajar berlangsung terdapat $34 \%$ siswa tidak mendengarkan pelajaran yang diterangkan oleh guru, saat proses balajar berlangsung jika ada teman mengobrol maka siswa lain juga akan ikut mengobrol tanpa memperdulikan pembelajaran yang berlangsun. Hal seperti ini akan mengganggu proses belajar mengajar yang ada didalam kelas, sehingga kelas 
tidak kondusif. Kedekatan teman sebaya dapat membentuk suatu kelompok yang erat.

Prestasi belajar diperoleh peserta didik akan meningkat apabila kegiatan belajarnya guru bisa menggunakan atau mengaplikasikan model pembelajaran guna dapat menumbuhkan dorongan keyakinan siswa dengan cara memanfaatkan berbagai macam metode pembelajaran yang menyenangkan. Dalam kegiatan pembelajaran selalu diikuti dengan kegiatan pengevaluasian agar dapat mengetahui kemampuan siswa, dengan dibuktikan dari nilai prestasi belajar yang diperoleh maka dari situ terlihat manakah siswa yang cepat dan lambat dalam menerima materi yang disampaikan. Ada beberapa faktor yang bisa memberikan pengaruh prestasi dalam belajar siswa menurut Slameto (2013) ) faktor dalam diri adalah sesuatu yang bersifat jasmani, psikologi dan factor luar adalah karena disekitar lingkungannya. Indikator dari prestasi belajar meliputi nilai raport semester ganjil 2017/2018 kelas XI IPS SMAN 1 Kedamean.

Tujuan dari penelitian ini: pertama untuk menganalisis hubungan antara efikasi diri dengan prestasi belajar siswa, yang kedua adalah menganalisis hubungan antara gaya belajar dengan prestasi belajar siswa, dan yang ketiga adalah untuk menganilisis hubungan anatara lingkungan teman sebaya dengan prestasi belajar siswa.

\section{METODE}

Jenis dalam penelitian ini yaitu eksplanatori, penelitian ini mempunyai tujuan menguji teori serta hipotesis yang dipergunakan agar dapat menolak serta memperkuat suatu teori ataupun hipotesis dari hasil penelitian yang telah digunakan. Untuk pendekatan penelitian ialah menggunakan pendekatan kuantitatif.

Rancangan penelitian digunakan dalam melakukan proses penelitian, dimana rancangan penelitian ini digunakan peneliti untuk menjelaskan suatu variable yang dipergunakan dalam penelitian. Adapun rancangan penelitiannya adalah.

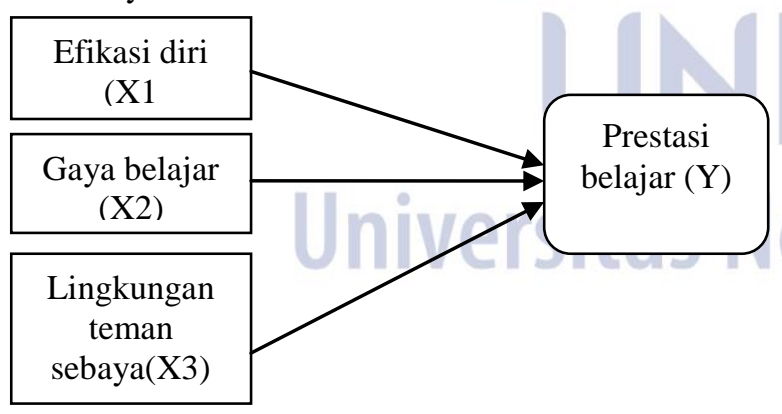

Gambar 1. Model Rancangan Penelitian

Sumber : data diolah peneliti, (2018)

Dari gambar rancangan penelitian yang ada diatas dapat menjawab hipotesis dari penelitian yakni : yang pertama diduga ada hubungan yang signifikan efikasi diri dengan prestasi belajar siswa, yang kedua diduga ada hubungan signifikan antara gaya belajar dengan prestasi belajar siswa, dan yang ketiga diduga ada hubungan signifikan antara lingkungan teman sebaya dengan prestasi belajar siswa.
Di dalam penelitian ini jumlah populasi seluruhnya adalah 123 siswa. Dan sampel yang dipergunakan adalah 94 siswa. Dimana untuk menentukan jumlah sampel yaitu dengan teknik simple random sampling. Untuk memperoleh data diperlukan data primer dan sekunder Dimana data primer di dapatkan dari hasil jawaban responden berbentuk kuisioner tertutup yang disebar kepada sampel. Kemudian data sekunder didapatkan dari nilai Raport dari guru ekonomi kelas XI IPS SMAN 1 Kedamean.

\section{HASIL DAN PEMBAHASAN \\ Hasil}

Dari penelitian yang dujikan kepada sampel yang berjumlah 94 siswa kelas XI IPS, diperoleh hasil berikut:

Tabel 1 Kategori Interval Efikasi diri

\begin{tabular}{|c|c|c|c|}
\hline Interval & Kategori & $\begin{array}{c}\text { Jumlah } \\
\text { Responden }\end{array}$ & Prosentase \\
\hline $93-109$ & Tinggi & 5 & $5,3 \%$ \\
\hline $76-92$ & Sedang & 41 & $43,6 \%$ \\
\hline $59-75$ & Rendah & 48 & $51 \%$ \\
\hline Jumlah & $=$ & 94 & $100 \%$ \\
\hline \multicolumn{3}{|c}{ Sumber : data diolah peneliti (2018) }
\end{tabular}

Dapat diketahui dari data yang ada diatas siswa yang mempunyai efikasi kategori tinggi sebanyak 5 responden atau sebesar $5,3 \%$, siswa yang memiliki efikasi diri sedang yaitu 41 responden atau sebesar 43,6\% dan siswa yang memiliki efikasi diri kategori rendah memperoleh 48 responden atau sebesar $51 \%$.

Tabel 2 Kategori Interval Gaya Belajar

\begin{tabular}{|c|c|c|c|}
\hline Interval & Kategori & $\begin{array}{c}\text { Jumlah } \\
\text { Responden }\end{array}$ & Prosentase \\
\hline $82-95$ & Tinggi & 23 & $24,4 \%$ \\
\hline $68-81$ & Sedang & 56 & $59,6 \%$ \\
\hline $54-67$ & Rendah & 15 & $15,9 \%$ \\
\hline Jumlah & \multicolumn{4}{|c|}{ Sumber $:$ data diolah peneliti (2018) }
\end{tabular}

Dapat diketahui data diatas siswa yang mempunyai gaya belajar kategori tinggi sebanyak 23 responden atau sebesar $24,4 \%$ sedangkan siswa yang mempunyai gaya belajar kategori sedang sebanyak 56 atau sebesar $59,6 \%$, dan siswa yang mempunyai gaya belajar kategori rendah sebanayak 15 responden atau sebesar $15,9 \%$.

Tabel 3 Kategori Interval Lingkungan Teman Sebaya

\begin{tabular}{|c|c|c|c|}
\hline Interval & Kategori & $\begin{array}{c}\text { Jumlah } \\
\text { Responden }\end{array}$ & prosentase \\
\hline $87-101$ & Tinggi & 22 & $23,4 \%$ \\
\hline $72-86$ & Sedang & 58 & $61,7 \%$ \\
\hline $57-71$ & Rendah & 14 & $14,8 \%$ \\
\hline Jumlah & $=$ & 94 & $100 \%$ \\
\hline
\end{tabular}

Sumber : data diolah peneliti (2018)

Dapat diketahui dari data diatas bahwa siswa mempunyai lingkungan teman sebaya kategori tinggi adalah sebanyak 22 responden atau sebesar $23,4 \%$, siswa yang memiliki lingkungan teman sebaya dalam kategori 
sedang sebanyak 58 atau $61,7 \%$ kemudian siswa yang memiliki lingkungan teman sebaya dalam kategori rendah adalah 14 responden atau $14,8 \%$.

Tabel 4 Kategori Nilai Berdasarkan KKM

\begin{tabular}{|c|c|c|}
\hline Nilai & $\begin{array}{c}\text { Jumlah } \\
\text { responden }\end{array}$ & prosentase \\
\hline$\geq 75$ & 72 & $76,5 \%$ \\
\hline$\leq 75$ & 22 & $23,4 \%$ \\
\hline Jumlah & 94 & 100 \\
\hline
\end{tabular}

Sumber : data diolah peneliti (2018)

Dengan table kategori nilai yang ada diatas bahwa siswa mendapatkan nilai diatas KKM 72 responden sebesar 76,5\%. Sedangkan siswa yang mendapatkan nilai dibawah KKM adalah 22 responden atau sebesar $23,4 \%$.

Tabel 5 Kategori Tingkat korelasi

\begin{tabular}{|l|l|}
\hline \multicolumn{1}{|c|}{ Interval koefisien } & \multicolumn{1}{|c|}{ Tingkat hubungan } \\
\hline $0,00-0,199$ & Sangat rendah \\
$0,20-0,399$ & rendah \\
$0,40-0,599$ & sedang \\
$0,60-0,799$ & kuat \\
$0,80-1,000$ & sangat kuat \\
& \\
\hline
\end{tabular}

Sumber : Sugiyono, 2016

Tabel 6 hasil uji korelasi product moment

\section{Correlations}

\begin{tabular}{|c|c|c|c|c|c|}
\hline & & $\mathrm{Y}$ & $\mathrm{X} 1$ & $\mathrm{X} 2$ & X3 \\
\hline \multirow[t]{3}{*}{$Y$} & $\begin{array}{c}\text { Pearson } \\
\text { Correlation }\end{array}$ & 1 & $.417^{* *}$ & $.444^{* *}$ & $.424^{* *}$ \\
\hline & Sig. (2-tailed) & & .000 & .000 & .000 \\
\hline & $\mathrm{N}$ & 94 & 94 & 94 & 94 \\
\hline \multirow[t]{3}{*}{$\mathrm{X} 1$} & $\begin{array}{c}\text { Pearson } \\
\text { Correlation }\end{array}$ & $.417^{\text {** }}$ & 1 & $.957^{* *}$ & $.973^{* *}$ \\
\hline & Sig. (2-tailed) & .000 & & .000 & .000 \\
\hline & $\mathrm{N}$ & 94 & 94 & 94 & 94 \\
\hline \multirow[t]{3}{*}{$\mathrm{X} 2$} & $\begin{array}{c}\text { Pearson } \\
\text { Correlation }\end{array}$ & $.444^{* *}$ & $.957^{* *}$ & 1 & $.930^{* *}$ \\
\hline & Sig. (2-tailed) & .000 & .000 & & .000 \\
\hline & $\mathrm{N}$ & 94 & 94 & 94 & 94 \\
\hline \multirow[t]{3}{*}{$\mathrm{X} 3$} & $\begin{array}{c}\text { Pearson } \\
\text { Correlation }\end{array}$ & $.424^{* * *}$ & $.973^{* *}$ & $.930^{* *}$ & \\
\hline & Sig. (2-tailed) & .000 & .000 & .000 & \\
\hline & $\mathrm{N}$ & 94 & 94 & 94 & 94 \\
\hline
\end{tabular}

**. Correlation is significant at the 0.01 level (2-tailed)

Sumber : data diolah peneliti (2018)

Nilai signifikan X1 yaitu $0,000<0,05$ maka artinya adalah efikasi diri terdapat hubungan signifikan dengan prestasi belajar. Arah hubungan yang terjadi yaitu korelasinya bersifat positif. Diketahui nilai signifikan X2 yaitu $0,000<0,05$ artinya adalah gaya belajar terdapat hubungan yang positif dengan prestasi belajar. Arah hubungan yang terjadi yaitu korelasinya bersifat positif.
Nilai signifikan $\mathrm{X} 3$ yaitu $0,000<0,05$ maka artinya adalah lingkungan teman sebaya memiliki hubungan signifikan dengan prestasi belajar. Arah hubungan yang terjadi yaitu korelasinya bersifat positif.

\section{Pembahasan}

Hubungan efikasi diri dengan prestasi belajar ekonomi siswa kelas XI IPS SMAN 1 Kedamean

Berdasarkan hasil output menggunakan korelasi product moment, maka diperoleh variable efikasi diri (X1) memiliki nilai signifikan $0,000<0,05$ artinya efikasi diri terdapat hubungan dalam menjelaskan perubahan prestasi belajar ekonomi siswa. Dari hasil korelasi tersebut maka dapat diketahui arah hubungan yang terjadi yaitu korelasinya adalah bersifat positif, artinya tingginya efikasi diri akan menghasilkan prestasi belajar yang tinggi. Dengan memperhatikan nilai koefisien korelasi sebesar 0,417 serta memperhatikan pendapat dari Sugiyono (2016) nilai korelasi tepat diinterval 0,40 0,599 membuat tingkatan hubungannya yang terjadi adalah bersifat sedang, sehingga merasakan siswa- siswi kurang untruk mengekspresikan dirinya ,sehingga mereka juga merasakan tidak nyaman juga dalam kemampuan ia miliki, sehingga dapat berhubungan dengan prestasi belajarnya.

penyebabnya adalah siswa - siswi tidak bisa mengekspresikan diri mereka sendiri untuk meningkatkan kempauannya, sehingga berhubungan dengan prestasi belajarnya.Sama halnya dengan menurut Winkel dalam Bekti (2014) prestasi belajar ditentukan oleh beberapa alas an seperti intelegensi, motivasi, sikapa atau gaya belajar, self efficacy, minat serta kondisi fisik. Dengan siswi yang mempunyai efikasi tinggi mereka akan lebih memiliki keyakinan yang kuat dan tekun terhadap usaha dan kemampuanny, sehingg prestasi belajar siswa yang didapatkan menjadi lebih optimal. Tetapi siswa yang mempunyai efikasi diri rendah mereka akan cenderung kurang percaya diri. Dari fenomena itu bisa dilihat peneliti pada siswa kelas XI ips SMAN 1 Kedamean.

Siswa merasakan kurangnya kenyamanan dan hilangnya kepercayaan diri guna meningkatkan potensi yang ia miliki. Sesuai dengan pernyataan Mukhid (2009) seseorang dapat sukses dalam tugas-tugas dan prestasi belajarnya, jika keyakinan dalam penilaian diri yang berkenaaan dengan kompetensinya tinggi. Penilitan juga diperkuat peneliti yang ada sebelumnya yaitu $\mathrm{Rr}$ Nanda (2013:7) menyatakan bahwa "adanya hubungan positif yang signifikan antara efikasi diri akademik dengan prestasi belajar siswa SMK Negeri 1 Purbalingga". Dari penelitian yang terdahulu tersebut menyatakan bahwa ada hubungan efikasi diri dengan prestasi belajar. secara parsial maupun simultan.

Hubungan gaya belajar dengan prestasi belajar ekonomi siswa kelas XI IPS SMAN 1 Kedamean.

Berdasarkan hasil output menggunakan uji korelasi product moment, maka diperoleh Gaya belajar (X2)memiliki nilai signifikan $0,000<0,05$ artinya gaya belajar terdapat hubungan dalam menjelaskan perubahan dalam prestasi belajar ekonomi siswa. Dari hasil korelasi tersebut maka dapat diketahui arah hubungan yang terjadi 
yaitu korelasinya adalah bersifat positif, artinya tingginya gaya belajar akan menghasilkan prestasi belajar yang tinggi. Dengan memperhatikan nilai koefisien korelasi sebesar 0,444 serta memperhatikan pendapat dari Sugiyono (2016) jika nilai korelasi ada pada interval 0,40 - 0,599 tingkat hubungan yang terjadi adalah bersifat sedang ,penyebabnya adalah siswa kurang aktif untuk merespone informasi yang diperolehnya dan kurang aktif dalam bertanya jawab ketika pembelajaran berlangsung.

Sama halnya dengan menurut Winkel dalam Bekti (2014) prestasi belajar ditentukan oleh beberapa alasan yaitu intelegensi, motivasi, sikap atau gaya belajar, efikasi diri, minat dan juga kondisi fisik. Siswa mampu berinteraksi dengan orang lain dengan baik, mampu berkomunikasi dua arah yang seimbang dan bisa saling dipahami dan memahami satu sama lain siswa di SMA ini memiliki gaya belajar cukup, tetapi gaya belajar perlu untuk ditingkatkan agar siswa lebih aktif untuk merespone informasi yang diperolehnya, aktif dalam bertanya jawab jika proses pembelajaran berlangsung.

Hal tersebut sesuai dengan pernyataan De Potter (2009:85) yang menyatakan gaya belajar mempunyai peranan penting yaitu berguna untuk saringan pembelajaran, pemrosesan serta komunikasi siswa dalam meningkatkan belajarnya. Penelitian ini diperkuat peneliti yang terdahulu yaitu Emila (2015:5) menyatakan "ada hubungan yang signifikan antara gaya belajar dengan prestasi belajar siswa SD Negeri 2 Pringsewu Timur". Dari penelitian terdahulu tersebut menyatakan terdapat hubungan gaya belajar dengan prestasi belajar secara parsial maupun simultan .

Hubungan lingkungan teman sebaya dengan prestasi belajar ekonomi siswa kelas XI IPS SMAN 1 Kedamean.

Berdasarkan hasil output menggunakan uji korelasi product moment, maka diperoleh variabel lingkungan teman sebaya (X3) mempunyai nilai yang signifikan $0,000<0,05$ artinya variable ini terdapat hubungan dalam menjelaskan perubahan dalam prestasi belajar ekonomi siswa. Dari korelasi maka dapat diketahui arah hubungan yang terjadi yaitu korelasinya adalah bersifat positif, artinya tingginya variable ini akan menghasilkan prestasi belajar tinggi. Memperhatikan nilai koefisien korelasi 0,424 serta memperhatikan pendapat dari Sugiyono (2016) kalau nilai korelasi diinterval 0,40 0,599 mengakibatkan tingkat hubungannya yang terjadi adalah bersifat sedang ,penyebabnya adalah siswa kurang memperhatikan ketika pembelajaran berlangsung siswa mengobrol dengan teman-temanya jadi membuat pelajaran yang didapat tidak diserapnya dengan baik sehingga akan mempengaruhi prestasi belajar dan kriteria kelulusan minimum siswa.

Sama halnya dengan menurut Desmita (2014) bahwa terbentuknya lingkungan teman sebaya merupakan berasal dari kegiatan ataupun aktivitas yang sama, bersekolah yang sama dan juga berpartisipasi dalam organisasi yang sama juga, Sehingga membuat teman sebaya akan menjadi teman belajar siswa tersebut, jika siswa dapat memiliki lingkungan positif akan dapat memberikan pengaruh pada peningkatan dalam prestasi belajarnya. Dengan siswa mimiliki lingkungan yang positif dan tinggi maka bisa memberikan pengaruh peningkatan pada prestasi belajarnya, namun berbanding terbalik kalau siswa mempunyai lingkungan yang negative, akan berdampak buruk pada prestasi belajar siswa. Siswa dikelas XI IPS ini memiliki lingkungan teman sebaya yang baik, namun perlu ditingkatkan lagi dengan kearah positif, untuk bisa meningkatkan prestasi belajarnya.

Sesuai pernyataan Santosa (2006) yang mengatakan lingkungan teman sebaya adalah mempunyai perananan tinggi dan penting dalam perkembangan pribadi setiap siswa. Penelitian ini diperkuat peneliti yang terdahulu yaitu Ade Ratna( 2018:10) menyatakan "terdapat hubungan yang positif dan signifikan antara lingkungan teman sebaya dengan prestasi belajar". Dari penelitian terdahulu tersebut menyatakan ada hubungan lingkungan teman sebaya dengan prestasi belajar siswa secara parsial maupun simultan

\section{PENUTUP}

\section{Simpulan}

Diperoleh dari hasil penelitian serta analisis simpulannya yaitu : 1. Ada hubungan signifikan efikasi diri dengan prestasi belajar siswa, 2. Ada hubungan yang signifikan gaya belajar dengan prestasi belajar siswa, dan yang ke 3 ada hubungan signifikan antara lingkungan teman sebaya dengan prestasi belajar ekonomi siswa kelas XI IPS di SMAN 1 Kedamean.

Saran

Saran yang dapat diberikan yaitu: Pertama siswa diharapkan dalam dirinya memiliki keyakinan diri yang tinggi serta belajar yang teratur agar siswa lebih yakin dalam menyelesaikan tugas sehingga akan memperoleh prestasi belajar yang maksimal, keyakinan diri adalah peranan yang penting dalam setiap diri siswa untuk pencapaian prestasi belajar. Kedua diharapkan siswa dapat mengenali gaya belajar yang efektif, gaya belajar yang efektif digunakan dalam belajar supaya dalam belajar tidak mudah jenuh atau malas belajar, saat berlangsungnya pembelajaran diharpkan siswa untuk memperhtaikan pembelajaran berlangsung tidak mengobrol dan bercanda.

Ketiga mempunyai lingkungan teman sebaya yang positif, siswa yang memiliki lingkungan teman sebaya yang positif akan memanfaatkan lingkungannya sebagai tempat belajar, tetapi jika lingkungan sebaya yang negatif maka siswa akan berperilaku menyimpang seperti kenakalan remaja, diharapkan juga kepada guru untuk bisa memberikan keadaan belajar dengan menarik serta siswa tudak mudah jenuh dapat ikut berperan serta dalam memperbaiki prestasi belajar siswa agar siswa lebih mendapatkan nilai yang maksimal dalam prestasi belajarnya.

\section{DAFTAR PUSTAKA}

Arifin, Muhammad. 2014. "Hubungan Kemampuan Efikasi Diri Dan kemampuan Kependidikan Dengan Kesiapan Menjadi Guru TIK Mahasiswa PendidikanTeknik 
Informatika". Jurnal Teknologi Dan kejuruan ,Vol.37, No 2, September 2014. Hal 129-136.

Bekti Susilo Apsari, Wahyu Adi dan Dini Octoria. 2014. Pengaruh Efikasi Diri, Pemanfaatan Gaya Belajar dan Lingkungan Teman Sebaya terhadap Prestasi Belajar Akuntansi SMK Negeri 1 Surakarta. Jurnal Pendidikan Ekonomi (JUPE).Vol. 3(1):hal.91-102

Desmita. 2014. Psikologi Perkembangan Peserta Didik .Bandung : PT Remaja Rosdakarya

DePotter, Bobbi dkk. 2009. Quantum Teaching. Mempraktikkan Quantum Learning di ruangruang kelas. Bandung: Kaifa.

Ghufron, Nur dan Rini Risnawita. 2014. Teori Teori Psikologi. Yogyakarta: ArRuzz Media.

Gunawan, Adi. 2006. Genius Learning Strategi. Jakarta: Gramedia Indonesia

John W.Santrock (2009). Psikologi Pendidikan. Jakarta: Salemba Humanika.

Junierissa Marpaung. 2015. Pengaruh Gaya Belajar Terhadap Prestasi Belajar Siswa Jurnal KOPASTA, 2 (2) $2015 . \quad$ Hal 13 - 17

Kiranjit Kaur Balbir Sing,Mohamad Jafre Zainol Abidin, Abbas Ali Rezaee, Helan Nor Abdulla., 2011 "Learning Styles and Overall Academic Achievement in a Specific Educational System”. International Journal of Humanities and Social Science, Vol. 1 (10)

Mukhid ,Abdul. 2009. Self-Efficacy (Prespektif Teori Kognitif Sosial dan Implikasinya terhadap Pendidikan). Tadris. Volume 4.Nomor 1.Hal 107-122.

Santoso, Slamet. 2006. Dinamika Kelompok. Jakarta: Bumi Aksara

Slameto. 2013. Belajar Dan Faktor-Faktor yang Mempengaruhinya. Jakarta: Rineka Cipta

Sugiyono.2016.Metode Penelitian Kuantitatif,Kualitatif dan $R \& D$. Bandung: Alfabeta.

Slavin, Robert E .(2008). Psikologi Pendidikan Teori dan Praktik. Terj. Marianto Samosir. Jakarta: PT Indeks.

Wahyuni ,Sri. 2013. Hubungan Efikasi Diri Dan Regulasi Emosi Dengan Motivasi Berprestasi Pada Siswa SMK Negeri 1 Samarinda. Ejournal psikologi 1 (1) (2013). Hal :88-95. 